\title{
A cooperação técnica do Brasil com a África: comparando os governos Fernando Henrique Cardoso (1995-2002) e Lula da Silva (2003-2010)
}

\author{
Brazil's technical cooperation with Africa: comparing \\ Fernando Henrique Cardoso's (1995-2002) and Lula da Silva's \\ (2003-2010) administrations
}

http://dx.doi.org/10.1590/0034-7329201500101

WILSON MENDONÇA JÚNIOR*

CARLOS AURÉLIO PIMENTA DE FARIA**

Rev. Bras. Polít. Int. 58 (1): 5-22 [2015]

Apenas muito recentemente, os estudos sobre a política externa brasileira têm buscado, de maneira mais sistemática, superar a sua tradição ensaística e normativa, no sentido da busca de um mais amplo lastreamento empírico. É também com o intuito de contribuir neste esforço de amadurecimento do subcampo que se apresenta este trabalho, cujo objetivo parece-nos táo singelo como relevante e inovador: analisar, comparativamente, a cooperação técnica provida pelo Brasil para os países africanos durante os governos Fernando Henrique Cardoso (1995 - 2002) e Lula da Silva (2003 - 2010). Buscaremos identificar e comparar o número e os tipos de acordos firmados, a sua dispersão geográfica no continente africano e a diversidade temática dos projetos de cooperação técnica horizontal, desenvolvidos pelo Brasil junto a seus mais tradicionais e aos novos parceiros africanos. Pretende-se analisar os dados comparativos com o fim de identificar, principalmente, traços característicos de uma política externa que se orientou, em distintos momentos, por meio de um potencial - apesar de subutilizado - poder brando. Outro aspecto que nos motivou a escrutinar a dinâmica das atividades de cooperação técnica brasileira se relaciona à sua baixa politização, não obstante o evidente paradoxo, para grande parte da opinião pública, de um país em

\footnotetext{
* Instituto Brasileiro de Mercado de Capitais (IBMEC-MG), Belo Horizonte, MG, Brasil (wilson.mendonca@ibmecmg.br).

** Pontifícia Universidade Católica de Minas Gerais (PUC-Minas), Belo Horizonte, MG, Brasil (carlosf@pucminas.br).
} 
desenvolvimento como o Brasil ser reconhecido como referência internacional nas atividades de cooperação horizontal.

Para a consecução destes objetivos, o artigo está estruturado da seguinte maneira: na primeira seção, traçamos um breve panorama do desenvolvimento da Cooperação técnica entre países em desenvolvimento (CTPD) do Brasil. A segunda seção é dedicada a uma apreciação geral das relaçôes do Brasil com a África nos governos FHC e Lula. A terceira seção é iniciada por uma nota metodológica, onde apresentamos a maneira como foi feita a pesquisa no banco de dados do Departamento de Atos Internacionais (DAI) do Ministério das Relaçóes Exteriores. Em seguida, procedemos à comparação da CTPD provida pelo Brasil na África durante os dois governos em questão. Nas considerações finais, os padrôes descobertos são reconectados às diretrizes mais gerais da política externa dos governos FHC e Lula.

\section{Um panorama do Brasil na cooperação técnica entre os países em desenvolvimento}

Desde a década de 1940, a missão social da cooperação técnica internacional (CTI) não significou, para os tomadores de decisóes, a contrapartida ou o corretivo potencial que justificasse o seu pleno empreendimento, capaz, por exemplo, de estabelecer o equilíbrio entre o crescimento econômico e o benefício social. Porém, foi este viés que orientou a organização e o gerenciamento da CTI do Brasil, sobretudo até a década de 1980, com o objetivo de agregar sempre mais consumidores e produtos ao mercado nacional.

Além do papel histórico de captação do conhecimento e da tecnologia que coube à cooperação internacional brasileira, desde a transição para a industrialização no país, esta passaria a ser utilizada, tanto no nível bilateral, desde a década de 1930, quanto no nível multilateral, principalmente após a Segunda Guerra, "como financiadora social, valendo-se de estratégias e mecanismos para apoiar o desenvolvimento econômico, em razáo da redução dos recursos multilaterais para o desenvolvimento" (Valler Filho 2007, 91).

Durante o período áureo do sistema internacional de CTI - fim dos anos 1960 a início dos 1980 - condiçóes quase ideais foram criadas no Brasil para o desempenho dos agentes de cooperação. Eram elas, segundo Cervo:

a) inserção racional da CTI na política exterior; b) flexibilidade para aceitar fins próprios e não-próprios definidos para a CTI pelos países avançados; c) montagem de um sistema nacional articulado de gerência da cooperaçấo técnica; d) implantação de agências internas bem preparadas em termos de recursos humanos e equipamentos para cooperar; e) filosofia desenvolvimentista a impregnar a opinião pública. (Cervo 1994, 40) 
A CTPD brasileira, desde o início, mas sobretudo a partir da criação da Agência Brasileira de Cooperaçáo (ABC), em 1987, procurou diferenciar-se consideravelmente da cooperação técnica tradicional (ou "vertical"). Procurou-se esvaziar o discurso de assimetria entre prestador e recebedor, encurtando a distância entre os participantes da CTPD, justificando, assim, o sentimento de parceria que deveria forjar a aliança entre os membros do eixo Sul-Sul. Dessa forma, rejeitava-se o caráter de assimetria e de desigualdade entre prestador e receptor, táo presentes na cooperação Norte-Sul. (Valler Filho 2007)

Não obstante, no plano mais geral, é relevante ressaltar que, atualmente, a CTPD brasileira está de certa forma baseada em práticas e expectativas consolidadas em fóruns e organismos multilaterais que atuam há décadas na cooperação para o desenvolvimento. O modelo de concepçáo e de execução da CTPD brasileira procura refletir a influência das categorias de análise, dos métodos de trabalho, do instrumental e da própria lógica prevalecente no ambiente da cooperação multilateral internacional, o que tende a reduzir o hiato entre os processos mais modernos de accountability da cooperação promovida por países desenvolvidos, classificados como doadores oficiais e membros do Comitê de Assistência ao Desenvolvimento, em comparação com a cooperação entre países em desenvolvimento.

Articular a cooperação para elevar a competitividade das bases produtivas nacionais, como país prestador e recebedor de projetos, constituiu desafio à cooperaçáo brasileira. Para tanto, foram adotadas como diretrizes pela $\mathrm{ABC}$ a priorizaçáo de programas e projetos escolhidos com base no critério de qualidade, para valorizar a excelência nos âmbitos espacial e temático; a escolha de iniciativas dentro do marco de referência maior da política externa e das prioridades nacionais (Valler Filho 2007).

Após a constituição da ABC, elaborou-se no Brasil, de acordo com Valler Filho (2007), uma noção abrangente e complexa de cooperação internacional, ao ponto de se poder intercambiá-la com a noção de política exterior, haja vista a função de fomentadora do desenvolvimento nacional, requerida de ambas. Ademais, percebe-se uma evoluçáo conceitual no pensamento brasileiro e na prática política do país, principalmente nas duas últimas décadas, quando a CTI transitou de sua acepção original, como assistência técnica, para a da cooperação para o desenvolvimento.

Essa evolução conceitual concluiu-se no momento em que se percebeu a potencialidade da CTI promovida pelo sistema da ONU, que incluía a CTPD (Cooperação Técnica entre Países em Desenvolvimento). Sob o ponto de vista brasileiro, a cooperação assistencial passou a causar ojeriza, visto que se requeria da política exterior uma cooperação econômica, científica e tecnológica a implementar-se entre as partes, em condiçóes cada vez mais igualitárias, em contraponto às alianças tradicionais. "A CTI prestada pelo Brasil passa a integrar, progressivamente, a política exterior brasileira com finalidades não próprias, 
ou seja, para criar e aprofundar laços econômicos, tecnológicos e culturais." (Cervo 1994, 43)

As motivaçôes da CTPD brasileira estiveram, em sua origem, também associadas à necessidade de renovar o sistema de cooperação internacional, para reforçar as capacidades dos países em desenvolvimento e facilitar-lhes a busca do desenvolvimento sustentável. Nesse sentido, conforme explica Puente:

O Brasil identificou na CTPD uma forma de reforçar sua aproximaçáo com países da América Latina e com países africanos de língua portuguesa. Houve, portanto, na origem da cooperação técnica horizontal do Brasil uma conjugaçáo de elementos motivacionais geopolíticos (vizinhança, entorno geográfico), com fatores decorrentes de vínculos históricos e culturais, além de certo componente ético, baseado na solidariedade entre as naçôes em desenvolvimento. (Puente 2010, 114)

Antes de tratarmos, mais especificamente, da CTPD do Brasil com a África nos governos FHC e Lula, buscando comparar as iniciativas brasileiras nos dois períodos, apresentaremos a seguir, muito brevemente e de maneira geral, as relaçóes bilaterais durante os dois governos em questão, destacando o seu significado no âmbito mais abrangente das relaçóes internacionais do Brasil.

\section{As relações entre o Brasil e a África nos governos FHC e Lula da Silva}

O período que corresponde à gestão presidencial de FHC (1995-2002) desenrolou-se quando ainda se consolidava a nova ordem internacional do pós-Guerra Fria. A política externa brasileira, como é usual, não se restringiu ao âmbito comercial, mas levou em conta, ademais, certas estratégias políticas que, conforme o discurso oficial justificaram a seletividade das parcerias do país com o continente africano. Conforme Ribeiro, essas estratégias "[...] derivam de uma estratégia mais ampla, ou seja, do projeto de redefinição da inserção do país no sistema internacional" (Ribeiro 2008, 288). A institucionalização da Comunidade dos Países de Língua Portuguesa (CPLP), em 1996, que vinha sendo articulada desde o governo Sarney (1985-1989), e a reaproximação com a África do Sul pós-apartheid são iniciativas que ilustram esse formato seletivo de parceria com a África, que, não obstante, contribuiu para o estreitamento de relaçóes comerciais e para a concertação política entre as partes.

Contudo, acreditamos que foi o pragmatismo na esfera comercial, sobretudo, que norteou as açóes de maior relevo na África, com destaque para as trocas comerciais do Brasil com a Nigéria e com Angola, concentradas, mormente, em óleo bruto. Sinal claro dessa orientaçáo fora evidenciado quando FHC chefiava a pasta das relaçóes exteriores, durante o governo Itamar Franco (1993-1994). Segundo o próprio FHC, chanceler à época: 
[...] a insistência ou promoção de relaçôes com países africanos haveria sido um equívoco, tendo servido apenas para os militares brasileiros afirmarem uma pretensa hegemonia no Atlântico Sul, sem que o Brasil nada ganhasse em termos econômicos. (Cardoso 1993, 317)

Já como chefe do Executivo, após 1995, e dando prosseguimento ao processo seletivo de articulação de parcerias, que em ampla medida excluía a África de suas prioridades, embaixadas foram fechadas, durante sua gestão, em diversos países africanos: em Adis Abeba (Etiópia), Dar Es Salam (Tanzânia), Iaundé (Camarôes), Kinshasa (República Democrática do Congo), Lomé (Togo) e Lusaca (Zâmbia) (Ribeiro 2010). A diminuição da participação do Estado na economia, componente estratégico do projeto político implementado no período, relegou a África ao restrito investimento privado no que toca ao fomento e à prospecção de investimentos no continente, principalmente no setor de construção civil. Essa condição reduziu drasticamente o volume de recursos transacionados, sendo que os esforços foram concentrados na regionalização Platina e nas trocas com os países desenvolvidos. De acordo com dados de Saraiva (2010), o volume de comércio entre o Brasil e a África Negra na década de 1990 retornou ao que fora registrado nas décadas de 1950 e de 1960. Conforme o autor, em comparação com a década de 1980, na qual a corrente de comércio atingira $10 \%$, na década em análise o montante não compreenderia o total de $2 \%$ de produtos transacionados.

Apesar dessa conjuntura, a consolidação da CPLP revelou-se paradigmática, porquanto se tratava de um projeto político, que se iniciou no governo Sarney, mas que se institucionalizou no governo FHC, corroborando, pois, as diretrizes seletivas de sua gestão. Os países lusófonos, inseridos na política de seletividade do período, deram modesto alento às reduzidas relaçôes com a África, de onde podemos registrar, inclusive, alguns acordos de cooperação técnica entre países em desenvolvimento (CTPD), dentre os quais podemos destacar a criação do centro de treinamento técnico de Cazenga, em Angola, construído em 1998. Desse modo, segundo Ribeiro, torna-se possível sugerir que "a política externa brasileira em relação ao continente africano não chega a registrar mudanças drásticas de agenda, mas de intensidade" (Ribeiro 2010, 74).

É digno de menção, também, o apoio brasileiro à estabilização da paz em Angola, sob a égide das Naçóes Unidas, haja vista que o país liderou, durante a década de 1990, a missão Unavem, o que ocorreria depois também em Moçambique, em consonância com a política de seletividade que incorporava os países lusófonos na esfera estratégica do Brasil. (Hirst e Pinheiro 2008).

Interessante material, que sintetiza com detalhes as relaçóes do Brasil com a África durante o governo FHC, foi elaborado pelo embaixador e à época Diretor-Geral do Departamento de África e Oriente Próximo do Ministério das Relaçôes Exteriores, José Vicente de Sá Pimentel, e publicado em revista 
especializada, no ano de 2000. Dando destaque ao maniqueísmo das relaçóes com o continente africano, Pimentel estabelece dois grupos extremados de abordagem: os catastrofistas e os nostálgicos.

Os nostálgicos costumam sublinhar as nossas responsabilidades históricas e se queixam de que já não há uma política africana com brilho e ousadia comparáveis à dos anos 70. Proclamam que o Governo tem obrigação de fazer mais, em decorrência de nossa dívida irresgatável para com a África. Os catastrofistas brandem estatísticas e vociferam que o Brasil não tem mais nada a fazer com os africanos. [...] o que distingue, de fato, os catastrofistas é a descrença em que os africanos possam reverter esse quadro. Há gradações de racismo indisfarçáveis em seu pretenso realismo. (Pimentel 2000, 6)

Pimentel (2000) situa a política externa do Brasil para a África, em sentido amplo, entre os dois extremos, justificando essa postura com base na necessidade de seletividade das parcerias. Segundo o embaixador, seletividade

[...] não significa desinteresse pelas grandes causas comuns a todos os africanos - de resto, a toda a humanidade - como a busca da paz, o desenvolvimento econômico, a democracia, os direitos humanos. Denota, apenas, pragmatismo na alocação de recursos limitados. (Pimentel 2000, 7)

A falta de atratividade pelo continente africano, durante a gestão de FHC, é justificada pelo embaixador como decorrência dos seguintes condicionantes: do regionalismo no Cone Sul, da prioridade conferida às parcerias com os países desenvolvidos e de um ensaio de aproximação com o sudeste asiático. Outro ponto, entretanto, que é retomado como um óbice ao estreitamento de relaçôes comerciais, principalmente, diz respeito ao vínculo privilegiado dos países africanos com a União Europeia, que fora recentemente constituída após o Tratado de Maastricht, em 1992.

Com base no contexto descrito acima, avalia-se que a conjuntura da década de 1990 não teria propiciado ao país vislumbrar outro formato, ao menos no curto prazo, de ruptura do modus operandi brasileiro no período pós-Guerra Fria. A leitura do texto de Pimentel (2000), pelo menos no tocante à África, sugere que, no período, foi feita uma leitura determinista e inexorável, pelo menos no tocante à África, o que justificaria uma postura passiva do Brasil ante o vizinho no Atlântico Sul. Fica subentendida, nesse sentido, a interpretação segundo a qual a responsabilidade por iniciativas proativas - com o fim de retirar a África da marginalidade das relaçôes internacionais - caberia exclusivamente aos países ricos.

Há, no entanto, considerável mudança nas diretrizes das relações bilaterais entre o Brasil e a África ao longo dos dois mandatos presidenciais de Lula da Silva (2003-2010), notadamente em regióes sem vínculo tradicional com a diplomacia pátria. Isso, pelo menos, se levarmos em consideração os princípios e iniciativas que predominaram em grande parte da década de 1990. 
Na política externa de Lula da Silva, identifica-se, pois, o estreitamento de relaçóes com o continente africano e com outras regióes do chamado Sul Global, pensado como uma possibilidade da ampliar o poder de barganha do Brasil no sistema internacional. Ademais, o governo Lula empreendeu medidas administrativas no âmbito do Ministério das Relaçóes Exteriores para dinamizar a ampliação da presença brasileira no continente africano, merecendo destaque o desmembramento do Departamento da África e do Oriente Médio, que veio dar lugar à reativação de um Departamento dedicado exclusivamente para o continente africano (Ribeiro 2010). Ainda acerca do Itamaraty, acrescenta Visentini (2005):

O governo Lula devolveu ao Itamaraty a posição estratégica que anteriormente ocupara na formulação e execução da política exterior do Brasil, pois, no governo anterior, FHC dominara a parte política (“diplomacia presidencial”), e o ministro Malan, a agenda econômica internacional, restando ao Ministério das Relaçóes Exteriores apenas a parte técnico-burocrática das negociaçóes e o recebimento das críticas. (Visentini 2005, 389).

A política externa de Lula da Silva, portanto, deu ênfase à diversificação de parcerias, embalada, também, pelos fins pragmáticos da busca de alternativas ao esgotamento do modelo vertical de inserção internacional, sem desconsiderar, entretanto, a vertente ideológica da diplomacia solidária, responsável pela legitimidade e pela boa aceitação de suas diretrizes por grande parte da comunidade internacional. Não se limita ela, no entanto, à mera reprodução da Política Externa Independente e do Pragmatismo Responsável do passado: a ampliação e a horizontalização do diálogo com os países africanos tornam-se, desde o início do século 21, prementes para a consecuçấo dos propósitos de ambos os interlocutores (Hirst e Pinheiro 2008). Os laços étnicos e culturais, exclusivamente, não são mais vistos como suficientes para o estreitamento de relaçóes com a África se já o foram algum dia -, a pujança da economia africana e a sua expressiva demanda por mão de obra qualificada responderão, a partir desta primeira década do século 21, principalmente, como fator adicional a atrair a atenção brasileira, e não apenas, para o continente africano.

A (re)aproximação com a África, apesar do auspicioso crescimento de sua classe média e da enorme demanda por mão de obra qualificada, não responde apenas aos interesses e estratégias de curto prazo. $\mathrm{O}$ relançamento da política africana do Brasil durante o governo Lula inova desde a maneira de se abordar o relacionamento bilateral, não mais pelo discurso culturalista, mas agora pela abordagem da parceria horizontal, sem pré-condiçôes inegociáveis, em um esforço simbiótico de superação de fragilidades sociais de ambas as regiōes (Saraiva 2004). É por meio do reconhecimento da dívida do país com a África, contraída durante séculos de escravidão, que mancharam a nossa história, e pelo consentimento de que o Brasil não é uma fantasiosa "democracia racial" que agora regressa ao continente africano. Nesse sentido, uma política externa de associação anti-hegemônica, articulada ao 
Sul e ao Norte, de corte multipolar, pragmática e idealista, porém com interesses e valores comuns que necessitam ser tratados no plano prático, em especial nos múltiplos e simultâneos tabuleiros de negociação então em curso, mostrar-se-ia, segundo a percepçáo do período, a mais apta a promover o desenvolvimento social, no âmbito interno, e a justa representatividade, no plano internacional, de ambas as regióes em um sistema global de expressiva assimetria na esfera política e na econômica (Mendonça Júnior 2013).

$\mathrm{Na}$ vertente diplomática, em consonância com a estratégia que buscava equilibrar idealismo (laços culturais e políticas sociais) com pragmatismo (concertação política e aumento no fluxo de comércio), verificou-se a abertura e/ou reativação de 19 novas embaixadas em solo africano (Jorge 2011). No que diz respeito à chamada diplomacia presidencial, cabe recordarmos que, se FHC, como presidente, fez 5 viagens à África, tendo visitado apenas 3 países, Lula fez, durante os seus dois mandatos, 32 viagens, tendo visitado 21 países africanos (Faria e Paradis 2013). Esses dados das viagens do presidente refletem o teor da mudança de abordagem, tendo em vista a comparação com seu antecessor. Vale lembrarmos, ainda, que foi João Figueiredo o primeiro presidente sul-americano a visitar o continente africano em novembro de 1983.

Em resposta a esta estratégia do governo Lula, foram abertas em Brasília, no período, 17 novas embaixadas de países africanos ${ }^{1}$. No que diz respeito ao seu chanceler, o Ministro Celso Amorim visitou, durante sua gestão no governo Lula, 31 países africanos, em 67 viagens ao continente (Brasil 2012c).

Além disso, observa-se que a execução da política externa brasileira para a África distinguiu-se da prática desenvolvida pelos governos predecessores, que enfocaram sobremaneira as relaçóes do Brasil com os PALOP (Países Africanos de Língua Oficial Portuguesa). No governo de Lula da Silva, como será visto em mais detalhe na próxima seção, verificou-se um nítido esforço para a ampliação do raio de atuaçáo da diplomacia brasileira no continente africano, apesar de grande parte dos esforços diplomáticos e de cooperação técnica terem continuado se concentrando nos países lusófonos daquele continente. De forma sintética, a mudança de abordagem é definida por Saraiva (2004) da seguinte maneira:

[...] a novidade do discurso do presidente Lula é a sua ruptura com o cinismo do discurso culturalista. [...] ao sugerir um Brasil menos exótico e artificialmente africanizado em favor de um Brasil mais verdadeiramente africano, por meio do reconhecimento da herança perversa da escravidáo. [...] Essa linguagem é muito mais palatável para as lideranças africanas e mais próxima à realidade cotidiana dos descendentes dos africanos no Brasil.

1 Benim, Botsuana, Burkina Faso, Congo, Etiópia, Guiné-Conacri, Guiné-Equatorial, Guiné-Bissau, Mali, Malaui, Mauritânia, Namíbia, Quênia, Sudão. 
Ele propóe um encontro de iguais, relaçóes horizontais entre parceiros, no esforço comum da superação das dificuldades sociais e econômicas dos mais enfraquecidos dos dois lados do Atlântico Sul. (Saraiva 2004, 302)

Essa nova postura brasileira se coaduna com ambas as vertentes da dialética Idealismo-Pragmatismo, ao combinar o compromisso com uma ordem social e econômica mais justa e solidária, em uma postura dita "não indiferente" às mazelas que afligem os países menos desenvolvidos, consoante o discurso do ex-chanceler Celso Amorim, com o pragmatismo das coalizóes plurilaterais. $\mathrm{Na}$ esfera idealista-solidária, por exemplo, o governo brasileiro perdoou a dívida africana de alguns países em quase US\$ 1 bilhão. Apenas em Moçambique, em 2004, a renúncia da dívida atingiu o montante de 95\% (IPEA 2010). Nesse mesmo país, verifica-se a vertente pragmática da política africana de Lula da Silva, ao analisarmos o financiamento, com juros subsidiados pelo BNDES, da construçáo do aeroporto de Nacala, conduzida pela empresa brasileira Odebrecht (Dantas 2011).

$\mathrm{Na}$ próxima seção, por fim, com o intuito de ampliar o lastro empírico das análises sobre a retomada e repriorizaçâo das relaçôes entre Brasil e África, buscaremos analisar comparativamente a cooperação técnica provida pelo Brasil para os países africanos durante os governos Fernando Henrique Cardoso e Lula da Silva. Procuraremos identificar e comparar o número e os tipos de acordos firmados, a dispersão geográfica desses acordos e a diversidade temática dos projetos de cooperação técnica horizontal desenvolvidos pelo Brasil naquele continente. A fonte principal das informaçóes analisadas, ainda pouco explorada pela literatura acadêmica brasileira, é o banco de dados do Departamento de Atos Internacionais do Ministério das Relaçóes Exteriores.

\section{Comparando a CTPD provida pelo Brasil na África durante os governos FHC e Lula}

Antes de procedermos à comparação entre os dois governos, faz-se necessário explicitarmos alguns detalhes da metodologia empregada, o que é importante até porque ainda é pouco usual o recurso à importante fonte oficial por nós utilizada.

\section{A CTPD provida pelo Brasil na África nos governos FHC e Lula}

A Tabela 1 apresenta o número de acordos de CT firmados anualmente pelo Brasil com países africanos desde o primeiro ano do governo FHC (1995) até o final do governo Lula (2010), sendo também discriminados os países recipiendários. 
Tabela 1. Países africanos recipiendários de CT brasileira.

\begin{tabular}{|c|c|c|c|}
\hline Ano & $\begin{array}{l}\text { No de } \\
\text { acordos }\end{array}$ & $\begin{array}{l}\text { No de } \\
\text { países } \\
\text { africanos }\end{array}$ & Países \\
\hline 1995 & 2 & 1 & Namíbia \\
\hline 1996 & 3 & 3 & África do Sul, Angola e Egito \\
\hline 1997 & 0 & 0 & - \\
\hline 1998 & 4 & 3 & Cabo Verde, Guiné-Bissau e Moçambique \\
\hline 1999 & 2 & 2 & Angola e Moçambique \\
\hline 2000 & 6 & 4 & África do Sul, Angola, Nigéria e São Tomé e Príncipe \\
\hline 2001 & 12 & 5 & $\begin{array}{l}\text { Guiné-Bissau, Moçambique, Namíbia, São Tomé e Príncipe } \\
\text { e Tunísia }\end{array}$ \\
\hline 2002 & 7 & 5 & Angola, Cabo Verde, Guiné-Bissau, Senegal e Tunísia \\
\hline Subtotal FHC & 36 & 23 & \\
\hline 2003 & 36 & 6 & $\begin{array}{l}\text { África do Sul, Angola, Burkina Faso, Moçambique, } \\
\text { Namíbia e Sáo Tomé e Príncipe }\end{array}$ \\
\hline 2004 & 7 & 4 & Cabo Verde, Marrocos, Moçambique e Nigéria \\
\hline 2005 & 22 & 14 & $\begin{array}{l}\text { Angola, Argélia, Benim, Camarōes, Etiópia, Gâmbia, } \\
\text { Guiné-Bissau, Guiné-Equatorial, Moçambique, Nigéria, } \\
\text { Quênia, São Tomé e Príncipe, Senegal e Sudão }\end{array}$ \\
\hline 2006 & 14 & 9 & $\begin{array}{l}\text { Angola, Argélia, Benim, Botsuana, Cabo Verde, Gana, } \\
\text { Moçambique, Tunísia e Zâmbia }\end{array}$ \\
\hline 2007 & 44 & 11 & $\begin{array}{l}\text { Angola, Benim, Burkina Faso, Cabo Verde, Camarōes, } \\
\text { Congo, Gana, Guiné-Bissau, Moçambique, São Tomé e } \\
\text { Príncipe e Senegal }\end{array}$ \\
\hline 2008 & 42 & 14 & $\begin{array}{l}\text { Angola, Argélia, Cabo Verde, Gana, Guiné-Bissau, } \\
\text { Marrocos, Moçambique, Quênia, São Tomé e Príncipe, } \\
\text { Seicheles, Serra Leoa, Suazilândia, Tanzânia e Congo }\end{array}$ \\
\hline 2009 & 24 & 14 & $\begin{array}{l}\text { Benim, Burundi, Cabo Verde, Congo, Guiné-Equatorial, } \\
\text { Guiné-Bissau, Libéria, Líbia, Maláui, Mali, Moçambique, } \\
\text { São Tomé e Príncipe, Senegal e Togo. }\end{array}$ \\
\hline 2010 & 49 & 18 & $\begin{array}{l}\text { Angola, Argélia, Botsuana, Burkina, Camarōes, Congo, } \\
\text { Guiné-Bissau, Lesoto, Libéria, Mali, Moçambique, Nigéria, } \\
\text { Quênia, São Tomé e Príncipe, Tanzânia, Togo, Zâmbia e } \\
\text { Zimbábue }\end{array}$ \\
\hline Subtotal Lula & 238 & 90 & \\
\hline Total & 274 & 113 & \\
\hline
\end{tabular}

Fonte: Elaboração própria a partir de Brasil (2014a). 
Se, em seus oito anos de governo, FHC assinou 39 acordos de cooperaçáo técnica com países africanos, Lula, em igual período de oito anos, firmou 238, ou seja, um número quase seis vezes superior. Note-se, ademais, a grande ampliação do número de parceiros, que foi de 23 no primeiro período e de 90 no governo Lula (como fica evidente na tabela, vários países foram contabilizados mais de uma vez). A Figura 1 apresenta esses dados de uma outra maneira, evidenciando duas questôes importantes, quais sejam: que é a partir do final do segundo mandato de FHC que a CT com a África começa a deslanchar e que, durante o governo Lula, há um forte crescimento, ainda que não linear.

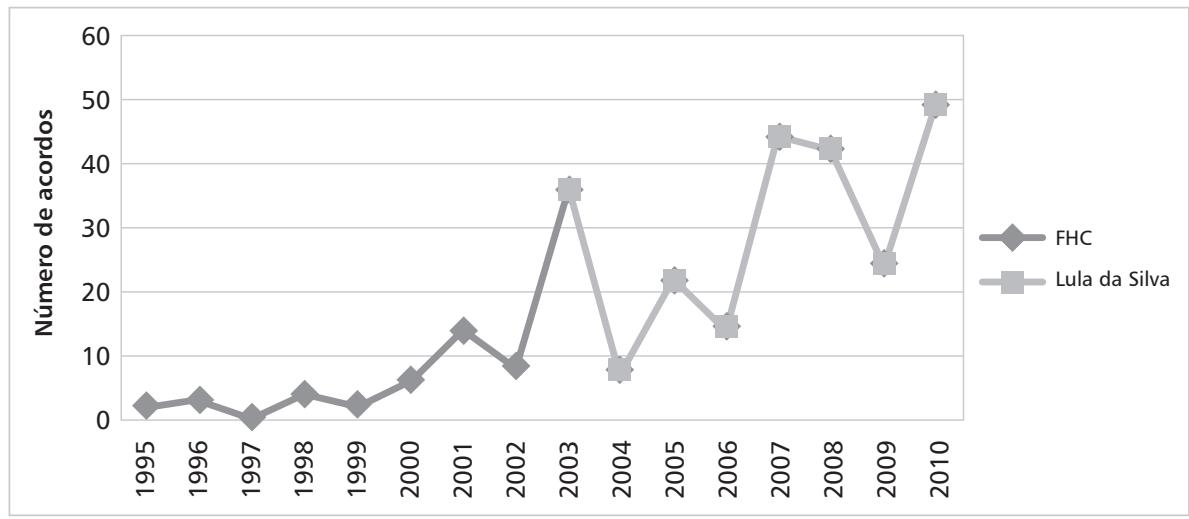

Figura 1. Número de acordos de CT bilaterais Brasil/África (1995-2010).

Fonte: Elaboração própria a partir de Brasil (2014a).

No que diz respeito aos países recipiendários, a Tabela 2 apresenta apenas o que chamamos de "novos parceiros" africanos, ou seja, aqueles que, durante os dois governos em questão, firmaram, pela primeira vez, acordos de CT com o Brasil.

Tabela 2. Novos parceiros africanos da CT brasileira.
FHC (1995-2002)
Lula da Silva (2003-2010)
4
16
Namíbia, África do Sul, Burkina Faso, Sudão, Guiné-Equatorial, Gâmbia, Etiópia, Benim,
Zimbábue, Tunísia Zâmbia, Suazilândia, Serra Leoa, Tanzânia, Maláui, Libéria, Líbia,
Burundi, Lesoto, Botsuana

Fonte: Elaboração própria a partir de Brasil (2014a).

O que a Tabela 2 evidencia é a grande expansão das fronteiras da CT brasileira na África durante os anos Lula. Isso porque o número de "novos parceiros" em solo africano foi quadruplicado (de 4 para 16). Não obstante, é importante destacar que os 4 novos parceiros estabelecidos no governo FHC dinamizam uma suposta nova fronteira austral do Brasil na África. 
De acordo com os dados compilados do sítio eletrônico do DAI, elaboramos a Tabela 3 com a discriminaçáo da natureza dos acordos de cooperação firmados com a África nos dois governos. Há quatro classificações principais de acordos de CT adotadas pelo Brasil: os protocolos de intençóes (PIs), os memorandos de entendimentos (MEs), os ajustes complementares (ACs) e os acordos gerais (AGs). Este último diz respeito, em tese, à primeira manifestação de interesses das partes em promover a cooperação, o que, vale ressaltar, na prática nem sempre corresponde ao primeiro ato de cooperação entre os países.

Tabela 3. Modalidades de acordos na CT bilateral (Brasil e África).

\begin{tabular}{|c|c|c|}
\hline Tipo de Acordo & FHC (1995-2002) & Lula da Silva (2003-2010) \\
\hline PI & 6 & 41 \\
ME & 3 & 28 \\
AC & 24 & 160 \\
AG & 3 & 9 \\
\hline Total & $\mathbf{3 6}$ & $\mathbf{2 3 8}$ \\
\hline
\end{tabular}

Fonte: Elaboração própria a partir de Brasil (2014b).

O protocolo de intençóes (PI) costuma ser utilizado para referir-se tanto aos acordos bilaterais quanto aos multilaterais. É utilizado para designar acordos menos formais que os tratados ou acordos complementares ou interpretativos de tratados ou convençóes anteriores. $\mathrm{Na}$ atividade diplomática cotidiana, tem sido usado, muitas vezes, para sinalizar um início de compromisso entre as partes (Brasil 2012b).

$\mathrm{O}$ memorando de entendimento (ME), nomenclatura comum para atos redigidos de forma simplificada, é destinado a registrar princípios gerais que orientarão as relaçóes entre as partes, seja nos planos político, econômico, cultural ou em outros. Contanto que não preveja "compromissos gravosos" para a Uniáo, pode normalmente entrar em vigor na data da assinatura. (Brasil 2012b)

Os ajustes complementares (ACs) são assinados para dar execução a outro ato internacional, anterior, devidamente concluído e em vigor, ou para discriminar áreas de entendimento específicas, abrangidas por aquele ato. Em decorrência disso, são normalmente colocados ao abrigo de um acordo-quadro ou acordo-básico (Brasil 2012b).

Ao analisarmos a Tabela 3, verifica-se um aumento expressivo durante o governo Lula da Silva, sobretudo, dos acordos complementares (567\%), o que, em tese, sinaliza para um aprofundamento dos protocolos de intenções (PIs) e dos memorandos de entendimento (MEs). Essa característica nos leva a inferir que parte desses acordos sofreram ajustes e incrementos, ressaltando a relevância 
dos acordos de cooperação técnica para o aprofundamento das relaçóes interregionais.

Por fim, é importante analisarmos, também, as áreas temáticas dos acordos de cooperação técnica firmados entre Brasil e África nos dois períodos em questão. A Tabela 4 sintetiza os resultados da pesquisa feita no banco de dados do DAI/MRE.

Tabela 4. Área temática dos acordos de CT Brasil e África.

\begin{tabular}{|c|c|c|}
\hline Área temática & FHC & Lula da Silva \\
\hline Administração Pública & 2 & 13 \\
\hline Agricultura & 2 & 29 \\
\hline Agropecuária & - & 6 \\
\hline Científica e Técnica & 2 & 1 \\
\hline Comissão Mista & - & 3 \\
\hline Cultura & 2 & 13 \\
\hline Defesa & 2 & 2 \\
\hline Desporto & - & 15 \\
\hline Direitos Humanos & - & 3 \\
\hline Econômica e Comercial & - & 1 \\
\hline Educação & 10 & 23 \\
\hline Energia & - & 9 \\
\hline Formação Profissional & 4 & 22 \\
\hline Fortalecimento Institucional & 1 & 1 \\
\hline Infraestrutura & - & 3 \\
\hline Meio Ambiente & - & 12 \\
\hline Mineração & 1 & 3 \\
\hline Pecuária & - & 7 \\
\hline Políticas Públicas & 1 & 16 \\
\hline Saúde & 4 & 44 \\
\hline Turismo & 2 & 3 \\
\hline Total & 33 & $229^{2}$ \\
\hline
\end{tabular}

Fonte: Elaboração própria a partir de Brasil (2014b).

2 Nestes montantes, incluímos apenas os acordos que já possuem uma área temática definida, excluindo, pois, os acordos genéricos de cooperação. 
O que se percebe inicialmente dos dados apresentados é que a CTPD brasileira com a África foi expandida durante o governo Lula, em contraste com o ocorrido durante o período FHC, não apenas no que diz respeito ao número de acordos e à diversidade de parceiros, mas também no tocante às áreas temáticas envolvidas. Outro ponto importante evidenciado na Tabela 4 é que os acordos feitos durante o governo Lula abarcam todas as áreas envolvidas naqueles firmados durante o governo anterior, tendo o arco temático se expandido em nove (09) novos campos. Ademais, no período Lula foi ampliado o número de acordos em todos os campos já desenvolvidos no governo FHC, com exceção da área "Científica e técnica", que sofreu redução, e das áreas de "Fortalecimento institucional" e de "Defesa", onde se manteve o mesmo número de acordos.

No que diz respeito aos dados da Tabela 4, vale ressaltar as áreas temáticas de maior concentraçáo de acordos, ponto esse em que há distinçôes interessantes entre os dois governos. No período FHC, o campo da Educação foi o preponderante, com dez (10) acordos firmados, seguido pela área da Formação Profissional (4) e da Saúde (4). Durante o governo Lula, o campo de maior destaque é o da Saúde, com 44 acordos, seguido não muito de perto pela Agricultura (29) e pela Educação (23). Talvez possamos pensar que os três campos de cooperação mais acionados pela CTPD prestada pelo governo Lula aos países africanos reflitam o ideário de compartilhamento de tecnologias autóctones brasileiras, que seriam específicas, por exemplo, de países tropicais. ${ }^{3}$ De qualquer forma, torna-se explícito, em decorrência do expressivo aumento da prestação de CT em algumas áreas destacadas na Tabela 4, o papel de "exportador de tecnologia social" (Stuenkel 2014), assumido pelo Brasil, em virtude, sobretudo, da busca de replicação de programas sociais bem sucedidos no âmbito nacional e que contam, progressivamente, com significativa expertise brasileira e com crescente aceitação por parte de países recipiendários, A exportação de "tecnologia social" e de expertise nos campos da agricultura e da saúde tropical tornou-se, durante o governo Lula da Silva, uma auspiciosa ferramenta de poder brando brasileira para o estreitamento das relaçóes bilaterais.

\section{Considerações finais}

Como é amplamente reconhecido (Saraiva 2012; Puente 2010; Penna Filho 2013; Pecequilo 2012; Visentini 2013, Cervo e Bueno 2008), um dos pontos estratégicos da política externa de Lula da Silva foi a intensa retomada do universalismo, com ênfase no diálogo Sul-Sul. Em sintonia com essa diretriz, a CT brasileira prestada para a África, como ficou aqui evidenciado, traduziu para o plano prático o discurso da diplomacia solidária, que norteou a gestáo deste presidente

3 Outra explicação possível, cuja pertinência não foi possível aos autores verificar, diz respeito a um possível diferencial no ativismo e na capacidade de articulação internacional dos distintos ministérios envolvidos. 
(Faria e Paradis 2013). Tornava-se premente a conquista de novos mercados e a aproximação de outros interlocutores, o que, segundo o discurso oficial, respondia pelos intentos de diversificação de parcerias e da reforma da governança global.

Ao lado da ativa diplomacia presidencial, responsável pelo expressivo número de 21 países africanos visitados, durante os oito anos do governo Lula, constatou-se o também considerável número de acordos de CT firmados, principalmente com países sem vínculo tradicional com o Brasil, como apresentamos na Tabela 2. Apenas no governo Lula da Silva foram assinados 16 acordos pioneiros de CT com novos parceiros africanos, quais sejam: Zâmbia, Gâmbia, Burkina Faso, Benin, Guiné Equatorial, Sudão, Serra Leoa, Suazilândia, Tanzânia, Zimbábue, Libéria, Lesoto, Burundi, Maláui, Líbia e Etiópia. .Grande parte desses países, inclusive, inauguraram embaixadas em Brasília nos oito anos do governo de Lula da Silva (Brasil 2012c).

Ao analisarmos a Tabela 1, pudemos identificar, de forma clara, a expressiva dispersão geográfica dos acordos de CT brasileiros na África, notadamente os que representam as novas parcerias. Se compararmos essa tabela com os dados do sítio eletrônico do MRE, verificamos que apenas o Burundi e a Suazilândia não foram agraciados com novas representaçóes diplomáticas brasileiras, inauguradas ou reabertas durante o governo de Lula da Silva, o que, por sua vez, corrobora o alinhamento dos acordos de CT com a agenda diplomática e com as estratégias propostas pela política externa de Lula da Silva. Identifica-se, ademais, a mencionada implementação da "diplomacia solidária", que não esconde o propósito de busca de uma ampla projeção internacional para o país e de maior interlocução com os eixos horizontal e vertical, o que pode ser comprovado também pelo aumento na demanda por projetos trilaterais na África com o envolvimento de países desenvolvidos em parceria com a expertise brasileira (Brasil 2012a).

Percebe-se, pois, que a Política Africana de Lula da Silva remonta aos princípios políticos e culturais que permearam a busca de articulação entre os países lusófonos desde a Política Externa Independente. Inova a política externa do ex-presidente, contudo, ao conciliar os ideais do universalismo, tradicionalmente caros à chancelaria brasileira, com os fins pragmáticos e estratégicos do diálogo SulSul, ao propiciar o aumento, intensificação e diversificação da projeção do Brasil no continente africano. Segundo o Ministro Marco Farani, diretor-geral da ABC durante o governo Lula, a instituição previa o aporte de 65 milhôes de dólares para pôr em prática a expansão dos projetos de CTPD para 37 países africanos, entre os anos de 2011 e 2013 (IPEA 2010).

Apesar de os projetos de cooperação técnica (CT) para a África nortearem-se pela demanda dos países recipiendários, sem a imposiçáa de condicionalidades para sua execução, consoante as palavras do Ministro Marco Farani ${ }^{4}$, podemos sugerir

4 O Ministro Marco Farani foi substituído pelo Ministro Fernando José Marroni de Abreu na direção da ABC no dia 21 de agosto de 2012. 
que os projetos de CTPD constituem-se em profícuos instrumentos de "poder brando" 5 da política externa brasileira (Puente 2010; Mendonça Júnior 2013). A agenda social do governo Lula, nesse sentido, coadunou-se com a sua diplomacia solidária (Faria e Paradis 2013), o que parece ter-lhe garantido respaldo, por grande parte dos países do Sul, para exportar boas práticas para os países africanos, sobretudo nas áreas da saúde e da agricultura. Nesse sentido, não foi casual a abertura de uma sucursal da Embrapa em Gana, em 2007, e de uma sucursal da Fiocruz em Maputo/Moçambique, conforme acordo assinado em 2008.

De qualquer forma, ao retomarmos a dualidade idealismo-pragmatismo da política externa de Lula da Silva, deparamo-nos, mais uma vez, com os princípios de solidariedade na formulação da agenda externa de sua gestão, desenvolvendose, pari passu, com a intenção de consolidar uma imagem de prestígio na comunidade internacional. A cooperaçáo técnica horizontal apresenta-se, pois, como ferramenta potencial para a política externa brasileira, que requer, contudo, maior aperfeiçoamento para se tornar mais abrangente e mais dinâmica no que diz respeito aos propósitos de estreitamento de relaçóes bilaterais e de projeção internacional do país nos distintos foros multilaterais de negociação.

\section{Referências bibliográficas}

BRASIL. Ministério de Relaçôes Exteriores. Agência Brasileira de Cooperaçâo. Disponível em $<$ http://www.abc.gov.br/ABC_por/WebForms/defaultaspx>. Disponibilidade: 12 fev. 2014 .

BRASIL. Ministério das Relaçôes Exteriores. Departamento de Atos Internacionais: Todos os atos. Disponível em: <http://dai-mre.serpro.gov.br/pesquisa_ato_todos $>$. Disponibilidade: 12 fev. $2014 b$.

BRASIL. Ministério das Relaçóes Exteriores. Disponível em <http://www.itamaraty.gov.br/>. Disponibilidade: 25 abr. 2014c.

CERVO, Amado Luiz Cervo. (1994). Socializando o desenvolvimento; uma história da cooperação técnica internacional do Brasil. Revista Brasileira de Política Internacional, v. 37, n. 1, p. 37-63.

DANTAS, Luiz Antônio. (2011). BNDES: áreas de comércio exterior. In: África e a agenda econômica do Brasil, Rio de Janeiro.

FARIA, Carlos Aurélio P.; PARADIS, Clarisse Goulart (2013). "Humanism and solidarity in Brazilian foreign policy under Lula (2003-2010): theory and practice". Brazilian Political Science Review.

HIRST, Monica; PINHEIRO, Letícia. (1995). A política externa do Brasil em dois tempos. Revista Brasileira de Política Internacional, Rio de Janeiro, v. 51, n. 2, p. 5-23, jul/dez.

5 O conceito de Soft Power foi cunhado por Joseph Nye, em 2004, e contrapóe-se à ideia de Hard Power, ou seja, a obtenção de objetivos próprios por meio da coerção com recursos militares ou econômicos. Soft Power, no entanto, seria a habilidade de alcançar propósitos por meio da cooptação, sem práticas coercitivas, mas por métodos de atração e de convencimento (Nye 2004). 
IPEA. (2010). Cooperaçáo brasileira para o desenvolvimento internacional: 2005-2009. Brasília: IPEA.

JORGE, Nedilson. (2011) AÁfrica na agenda econômica do Brasil: comércio e investimentos. In: África e a agenda econômica do Brasil, Rio de Janeiro.

MENDONÇA JÚNIOR, Wilson. (2013). Política externa e cooperação técnica: as relaçóes do Brasil com a África durante os FHC e Lula da Silva. Belo Horizonte: D'Plácido Editora. 167 p.

PECEQUILO, Cristina Soreanu. (2012). As relaçôes Brasil-Estados Unidos. Belo Horizonte: Fino Traço. 168 p.

PENNA FILHO, Pio. (2013). A Parceria Africana: as relações Brasil-África do Sul. Belo Horizonte: Fino Traço, 164 p.

PIMENTEL, José Vicente de Sá. (2000). Relações entre o Brasil e a África subsaárica. Revista Brasileira de Política Internacional, v. 1, n. 43, p. 5-23, 2000.

PUENTE, Carlos Alfonso Iglesias. (2010). A cooperação técnica horizontal brasileira como instrumento de política externa: a evolução da cooperaçáo técnica com países em desenvolvimento - CTPD - no período 1995-2005. Brasília: FUNAG. 340 p.

RIBEIRO, Cláudio Oliveira. (2008). Crise e castigo: as relações Brasil-África no governo Sarney. Revista Brasileira de Política Internacional, v. 2, n. 51, p. 39-59.

RIBEIRO, Cláudio Oliveira. (2010). Adjustment changes: a política africana do Brasil no pós-GuerraFria. Revista de sociologia e política. Curitiba, v. 18, n. 35, p. 55-79, fev.

SARAIVA, J.F.S. (2004). África e Brasil: o Fórum de Fortaleza e o relançamento da política africana do Brasil no governo Lula. In: COELHO, Pedro Motta Pinto; SARAIVA, José Flávio Sombra (Org.). Fórum Brasil-África: política, cooperação e comércio: IBRI.

SARAIVA, J.F.S. (2010). The new Africa and Brazil in the Lula era: the rebirth of Brazilian Atlantic Policy. Revista Brasileira de Política Internacional, v. 53, número especial, p. 169-182.

SARAIVA, J.F.S. (2012). África parceira do Brasil atlântico: relaçôes internacionais do Brasil e da África no início do século XXI. Belo Horizonte: Editora Fino Traço, 168 p.

STUENKEL, Oliver. (2014). O Brasil na África: uma ponte sobre o Atlântico?. Política Externa, Vol. 22, No 3, 2014, p. 65-73.

VALLER FILHO, Wladimir. (2007). O Brasil e a crise haitiana: a cooperação técnica como instrumento de solidariedade e de ação diplomática. Brasília: Funag. 396 p.

VISENTINI, Paulo Fagundes. (2005). De FHC a Lula, uma década de política externa (1995-2005). Revista de Ciências Sociais, Porto Alegre, v. 5, n. 2, p. 381-397, jul/dez.

VISENTINI, Paulo Fagundes. (2013). A projeção internacional do Brasil: 1930-2012. Rio de Janeiro: Elsevier. 224 p.

Recebido em 4 de março de 2015 Aceito em 26 de maio de 2015 


\title{
Resumo
}

É consensual entre os analistas da Política Externa Brasileira o reconhecimento da priorização do eixo Sul-Sul nas estratégias de inserção internacional do país durante o governo Lula da Silva, bem como o papel de destaque concedido ao continente africano. Com o intuito de dar lastro empírico às análises sobre a retomada e repriorização das relações entre Brasil e África, este trabalho pretende analisar comparativamente a cooperação técnica provida pelo Brasil para os países africanos durante os governos Fernando Henrique Cardoso (1995-2002) e Lula da Silva (2003-2010). Procura-se identificar e comparar o número e os tipos de acordos firmados, a dispersão geográfica desses acordos e a diversidade temática dos projetos de cooperação técnica horizontal desenvolvidos pelo Brasil naquele continente. A fonte principal dos dados analisados, ainda pouco explorada pela literatura acadêmica brasileira, é o banco de dados do Departamento de Atos Internacionais do Ministério das Relações Exteriores.

Palavras-chave: cooperação técnica internacional; diálogo Sul-Sul; Política Externa Brasileira; relações Brasil-África.

\begin{abstract}
The prioritization of the South-South axis during the Lula da Silva government is consensual among analysts of Brazilian Foreign Policy regarding its international insertion, as well as the prominent role given to the African continent. In order to provide empirical analysis to the reprioritization of relations between Brazil and Africa, this paper aims at comparing the technical cooperation provided by Brazil to African countries during FHC (1995-2002) and Lula da Silva (2003-2010) administrations. Its primary source of analyzed data, little explored by the Brazilian academic literature yet, was the databank of the Department of International Acts of the Ministry of External Relations.
\end{abstract}

Keywords: international technical cooperation, South-South dialogue; Brazilian Foreign Policy; Brazil-Africa relations. 